\title{
ANÁLISE DA EFICIÊNCIA DE ADSORÇÃO DO CORANTE VERMELHO DO CONGO POR SEMENTE DE MAMÃO FORMOSA (Carica papaya L.) SECA EM LEITO FIXO COM FLUXO DE AR PARALELO
}

\author{
A. L. ARIM ${ }^{1}$, L. M. RODRIGUES ${ }^{2}$ e A. R. F. de ALMEIDA ${ }^{1,2}$ \\ ${ }^{1}$ Programa de Pós-Graduação em Engenharia - Campus Alegrete/Bagé \\ ${ }^{2}$ Engenharia Química - Campus Bagé \\ Universidade Federal do Pampa - UNIPAMPA \\ E-mail para contato: andre.almeida@unipampa.edu.br
}

\begin{abstract}
RESUMO - Neste trabalho objetivou-se analisar a eficiência da adsorção do corante Vermelho do Congo por semente de mamão Formosa (Carica papaya L.) moída e seca em diferentes condições experimentais. $\mathrm{O}$ trabalho foi dividido em duas etapas. Primeiramente determinaram-se, com base em um planejamento experimental fatorial $2^{3}$, as condições favoráveis para o processo de adsorção do corante Vermelho do Congo com as sementes de mamão Formosa na forma moída e seca a $60^{\circ} \mathrm{C}$ por $24 \mathrm{~h}$ em estufa. Na segunda etapa, também com base em um planejamento experimental fatorial $2^{3}$, efetuou-se o estudo da influência do processo de secagem da biomassa sobre a umidade final e a eficiência de adsorção do corante Vermelho do Congo. Os resultados obtidos mostraram que o estudo do processo de secagem é de fundamental importância para o preparo do meio adsorvente, visto que as biomassas submetidas a diferentes condições de secagem apresentaram diferenças significativas nos valores de umidade final e eficiência de remoção do corante Vermelho do Congo.
\end{abstract}

\section{INTRODUÇÃO}

Estimativas indicam que entre 10 e $20 \%$ dos corantes usados no processamento fabril são perdidos durante as etapas de beneficiamento têxtil (LEVIN e PAPINUTTI, 2004). Isto ocorre devido a perdas que acontecem durante o processo de fixação do corante nas fibras. A remoção desses compostos dos rejeitos industriais é um dos grandes problemas ambientais enfrentados pelo setor têxtil (ZANONI e CARNEIRO, 2001).

De acordo com Durán et al. (2000), os corantes compreendem dois componentes principais, o grupo cromóforo, responsável pela cor, e o grupo funcional, que permite a fixação nas fibras do tecido. Existem vários grupos cromóforos utilizados atualmente, como, por exemplo, os grupos azo, azoxi, nitro, nitroso e quinona. Os mais representativos e largamente utilizados são os do tipo azo corantes (ZANONI e CARNEIRO, 2001).

De acordo com Axelson et al. (2008) Vermelho do Congo é um corante aniônico, cuja fórmula molecular é $\mathrm{C}_{32} \mathrm{H}_{22} \mathrm{~N}_{6} \mathrm{Na}_{2} \mathrm{O}_{6} \mathrm{~S}_{2}$, com massa molar de $696,66 \mathrm{~g} / \mathrm{mol}$ e estrutura molecular bastante complexa, contendo anéis aromáticos que dificultam a sua degradação química. Trata-se de um corante altamente resistente à degradação microbiana (BHAUMIK et al. 2013), classificado como diazo 
secundário por apresentar dois grupos de ligações estáveis azo $(-\mathrm{N}=\mathrm{N}-)$. A remoção desses corantes que contêm grupos azoaromáticos é extremamente relevante do ponto de vista ambiental, pois a maioria destes são tóxicos, de difícil degradação química e resistente a degradação microbiana, além de possuírem caráter mutagênico e cancerígeno (UMBUZEIRO, 2007).

Dentre os processos de tratamento de efluentes aplicados na indústria, a adsorção constitui um dos mais comumente utilizados pelo fato de ser bastante eficaz na remoção de espécies em soluções líquidas. Dependendo do material que é utilizado como adsorvente, pode-se tornar um método de baixo custo para o tratamento de efluentes (ZANONI e CARNEIRO, 2001).

Considerando a grande quantidade de efluente produzido pela indústria têxtil e o custo de seu tratamento, várias linhas de pesquisa têm focado esforços no estudo de adsorventes alternativos, também chamados de adsorventes não convencionais. Exemplos desses estudos são os que têm avaliado a capacidade de adsorção de materiais orgânicos do tipo talo de açaí e casca de cupuaçu (CARDOSO, 2012), bagaço de cana (ZHANG, 2011), bagaço de laranja (CAVICHIOLO, 2011), bagaço de maracujá (MENEZES, 2010), casca de pinhão (CALVETE, 2011) e casca de maracujá amarelo (PAVAN et al., 2008).

Segundo Melo (2010), o Brasil, devido ao seu clima tropical e subtropical, é um dos maiores produtores de mamão. Esta fruta, geralmente, é consumida in natura e processada na forma de geleia, doces e polpa. Por conta disso, uma porcentagem significativa de resíduo é gerada. No processamento industrial da fruta são considerados como resíduos a casca e as sementes.

No que se refere as sementes, que constituem em média $14 \%$ do peso bruto do fruto, estas são consideradas como material de descarte não só na indústria de alimentos, mas também no consumo doméstico. Uma alternativa de aproveitamento deste material de descarte pode ser a sua utilização como biomassa adsorvente no tratamento de efluentes têxteis. Estudos anteriores demonstram que esta aplicação tem apresentado bons resultados com corantes sintéticos do tipo azul de metileno (FRANCO, 2011) e Vermelho do Congo (ARIM, 2012a). Entretanto, estes estudos também indicam que para melhorar o poder adsorvente dessa biomassa é necessária a aplicação de operações unitárias para o preparo do material. Dentre as técnicas mais utilizadas para este fim, destacam-se a moagem e a secagem. A moagem, que é um processo puramente físico, tem como objetivo a diminuição do tamanho da partícula do material adsorvente e, consequentemente, o aumento da área superficial específica do leito no processo de adsorção (BESINELLA et al., 2009). Já a secagem, que é um processo simultâneo de transferência de calor e massa, tem como meta a redução do teor de água do material adsorvente, e, por consequência o aumento da porosidade intrapartícula e dos sítios de adsorção (GEANKPLIS, 1998).

De acordo com o exposto, este trabalho teve como objetivo estudar eficiência de adsorção do azo corante aniônico Vermelho do Congo por sementes de mamão Formosa moídas e desidratadas em secador de leito fixo com fluxo de ar paralelo em diferentes condições experimentais.

\section{MATERIAIS E MÉTODOS}

A biomassa vegetal empregada neste trabalho foram sementes de mamão Formosa (Carica papaya L.) nas condições fresca e moída e seca. Estas biomassas foram caracterizadas quanto à umidade em base úmida $\left(U_{B U}\right)$, diâmetro de médio de partículas $\left(d_{p}\right)$, densidade real $\left(\rho_{\text {real }}\right)$, densidade bulk $\left(\rho_{\text {bulk }}\right)$ e porosidade média do leito estático $(\varepsilon)$.

O efluente sintetizado em laboratório foi composto pelo corante aniônico Vermelho do Congo da marca MERCK em solução aquosa. Pela técnica da espectrofotometria na região do UV-Vis e com o 
uso de um espectrofotômetro, marca EQUILAM, modelo UV 755B, o efluente foi analisado no comprimento de onda do corante aniônico Vermelho do Congo equivalente a $500 \mathrm{~nm}$. Pela técnica da espectrofotometria foi construída uma curva de calibração do corante Vermelho do Congo para as diferentes concentrações e gerada uma equação de reta para posterior determinação da concentração de corante no efluente sintético. A equação da reta gerada pela curva de calibração, com coeficiente de determinação $\left(R^{2}\right)$ de 0,99974 , é mostrada pela Equação 1:

$C e=A b s / 0,03783$

na qual $A b s$ é a absorbância do corante medida no espectrofotômetro e $C e$ é a concentração de equilíbrio do corante na fase fluida $(\mathrm{mg} / \mathrm{L})$.

Para a determinação de condições favoráveis que pudessem ser aplicadas na análise do processo de adsorção do corante Vermelho Congo pelas sementes secas nas diferentes condições experimentais, efetuou-se um planejamento experimental fatorial $2^{3}$ em duplicata para a otimização das variáveis envolvidas no processo de adsorção. Nessa análise a otimização do processo foi feita usando amostras de sementes moídas e secas em estufa de circulação forçada, marca Nova Ética e modelo 400-5ND, a $60{ }^{\circ} \mathrm{C}$ por $24 \mathrm{~h}$, onde objetivou-se avaliar os efeitos principais e interações dos fatores relação massa de biomassa por volume de efluente $\left(M_{b i o} / V_{\text {efl }}\right.$ em 0,01 e $\left.0,02 \mathrm{~g} / \mathrm{mL}\right)$, tempo de contato da biomassa no efluente $\left(t_{\text {cont }}\right.$ em 15 e $\left.30 \mathrm{~min}\right)$ e concentração de efluente $\left(C_{e f l}\right.$ em 25 e $\left.50 \mathrm{mg} / \mathrm{L}\right)$ sobre a resposta eficiência de remoção do corante Vermelho do Congo. Os níveis deste planejamento experimental foram definidos com base em um trabalho anterior (ARIM, 2012a). Em suma, o processo de adsorção foi realizado através das etapas de mistura do efluente/biomassa em mesa agitadora da marca Nova Ética e modelo 109-1 a cerca de $250 \mathrm{rpm}$, centrifugação a $3400 \mathrm{rpm}$ por 30 minutos em uma centrífuga microprocessada da marca QUIMIS, modelo Q222TM216, com controle digital.

Tendo como base as repostas do planejamento experimental fatorial $2^{3}$, foi possível realizar o estudo da influência do processo de secagem sobre a eficiência de adsorção do corante Vermelho do Congo por sementes de mamão Formosa (Carica papaya L.). Para esta etapa, a preparação da biomassa foi feita utilizando um moinho de facas, marca MULTITEC e modelo A11 B S32, e um secador de bandejas com escoamento de ar paralelo da marca ECO Educacional. Na Figura 1 é apresentada uma fotografia ilustrativa do secador de bandeja com escoamento paralelo de ar.

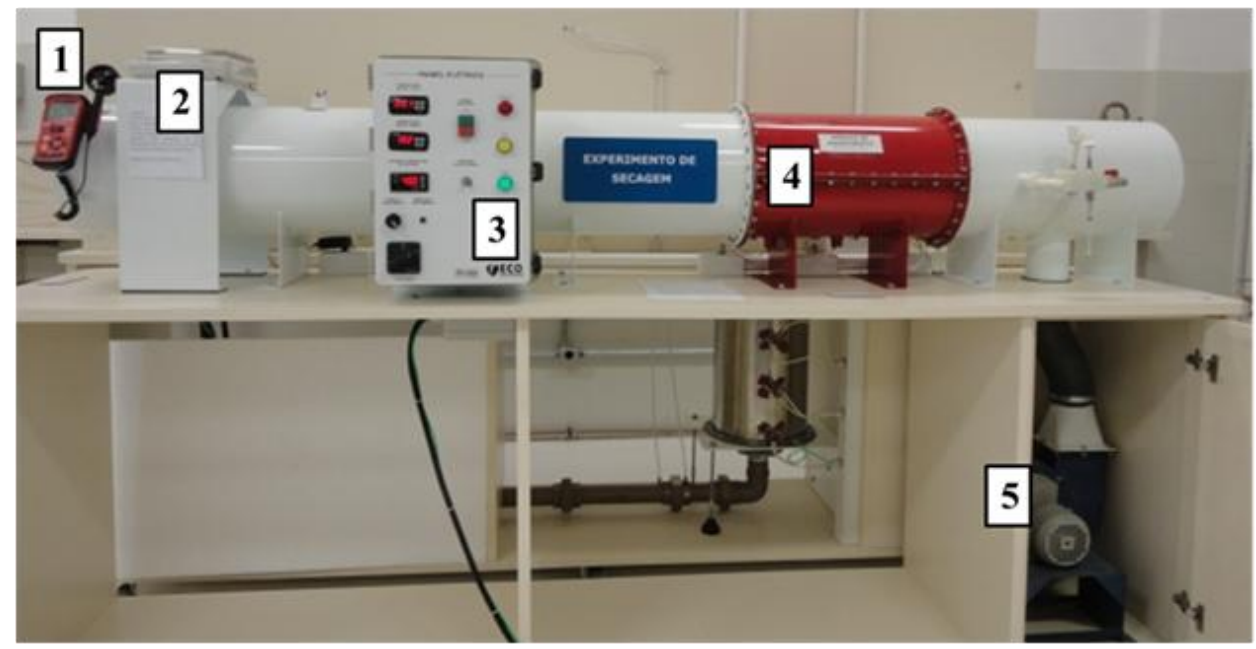

Figura 1 - Secador de bandeja com escoamento paralelo de ar.

(1) Anemômetro, (2) Balança, (3) Painel de controle, (4) Resistências elétricas e (5) Soprador centrífugo. 
Para a análise da influência do processo de secagem, efetuou-se um novo planejamento experimental fatorial $2^{3}$ visando avaliar os efeitos principais e interações dos fatores temperatura do ar de secagem $\left(T\right.$ em 40 e $\left.60{ }^{\circ} \mathrm{C}\right)$, velocidade do ar de secagem $(v$ em 1,0 e $2,0 \mathrm{~m} / \mathrm{s})$ e altura de bandeja ( $h$ em 5 e $10 \mathrm{~mm}$ ) sobre as respostas umidade final em base úmida e eficiência de adsorção do corante Vermelho do Congo por sementes de mamão Formosa (Carica papaya L.). Os níveis desse planejamento experimental foram definidos com base em um trabalho anterior (ARIM, 2012b).

\section{RESULTADOS E DISCUSSÃO}

Na Tabela 1 são apresentados os dados da caracterização física das sementes nas condições fresca e moída e seca em estufa a $60^{\circ} \mathrm{C}$ por $24 \mathrm{~h}$.

Tabela 1 - Caracterização física da semente de mamão Formosa (Carica papaya L.).

\begin{tabular}{cccccc}
\hline Amostra & $U_{B U}(\%)$ & $d_{p}(\mathrm{~mm})$ & $\rho_{\text {real }}\left(\mathrm{kg} / \mathrm{m}^{3}\right)$ & $\rho_{\text {bulk }}\left(\mathrm{kg} / \mathrm{m}^{3}\right)$ & $\varepsilon(-)$ \\
\hline Fresca & $84,00 \pm 1,17$ & $5,67 \pm 0,20$ & $1083,76 \pm 4,65$ & $672,95 \pm 15,20$ & $0,38 \pm 0,01$ \\
Moída e seca & $3,76 \pm 0,15$ & $0,74 \pm 0,05$ & $900,8 \pm 0,01$ & $195,2 \pm 0,008$ & $0,78 \pm 0,01$ \\
\hline
\end{tabular}

Observa-se na Tabela 1 que $U_{B U}$ das sementes frescas é de aproximadamente $84 \%$, enquanto a $U_{B U}$ das sementes moídas e secas é de aproximadamente $3,7 \%$. Em relação ao $d_{p}$, é verificado que diâmetro médio de partícula das sementes frescas é aproximadamente 7,5 vezes maior que o encontrado para as sementes moídas e secas. Esse fato esta relacionado com o processo de moagem aplicado no preparo do material. Para a $\rho_{\text {real }}$ é observado que o valor encontrado para as sementes frescas é em média $183 \mathrm{~kg} / \mathrm{m}^{3}$ maior que o encontrado para as sementes moídas e secas. Do mesmo modo, o valor da $\rho_{\text {bulk }}$ obtido para as sementes frescas é na ordem de $477 \mathrm{~kg} / \mathrm{m}^{3}$ maior que os obtidos para as sementes moídas e secas. Nos resultados da $\varepsilon$ é verificado que o leito constituído por partículas de sementes frescas possui uma $\varepsilon$ inferior à encontrada para o leito de partículas moídas e secas. Este resultado demonstra que o leito constituído por partículas de sementes moídas e secas possui mais espaços vazios que o leito constituído por partículas frescas.

Na Figura 2 é apresentado o diagrama de Pareto do planejamento experimental fatorial $2^{3}$ que foi efetuado para a determinação de condições favoráveis para o processo de adsorção do corante Vermelho do Congo pelas sementes de mamão Formosa (Carica papaya L.) secas em estufa de circulação forçada a $60{ }^{\circ} \mathrm{C}$ por $24 \mathrm{~h}$. A resposta obtida nesta análise foi a eficiência de adsorção do processo.

A Figura 2 mostra que a magnitude dos efeitos, com significado estatístico para $p=0,05$, que tiveram maiores influências sobre a resposta eficiência de adsorção foram a concentração do efluente, a relação massa de biomassa por volume de efluente e o tempo de contato. Observa-se que para a concentração do efluente, o seu aumento promove uma melhor eficiência de adsorção. Este fato está relacionado com a força motriz do processo de adsorção, onde o maior gradiente de concentração gera uma maior transferência de massa. No caso da relação massa de biomassa por volume de efluente é constatado que o seu aumento teve uma magnitude de efeito negativo. Observações visuais do experimento mostraram que quando se aumentava a massa de biomassa para um mesmo volume de efluente ocorriam aglomerações nos sólidos. Estas aglomerações podem ter causado uma diminuição da área de contato entre a biomassa e o efluente, diminuindo assim a eficiência do processo. Já para o tempo de contato foi obtida uma magnitude de efeito positivo, onde o aumento no tempo de contato de 15 para 30 minutos aumentou o valor da resposta eficiência de adsorção do processo. Isto está de acordo com o esperado, visto que o aumento no tempo do processo permite que o meio sólido adsorva mais massa da fase fluida. 


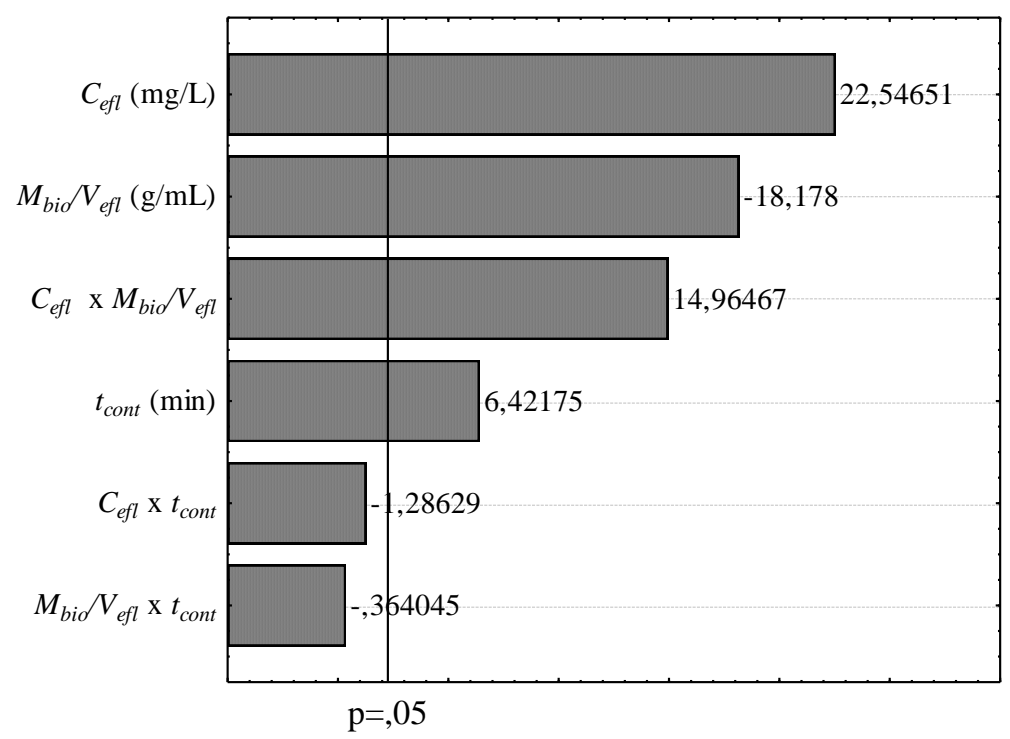

Figura 2 - Diagrama de Pareto para a análise de condições favoráveis para o processo de adsorção do corante Vermelho do Congo pelas sementes de mamão Formosa (Carica papaya L.) secas em estufa de circulação forçada a $60^{\circ} \mathrm{C}$ por $24 \mathrm{~h}$.

Com base nos resultados obtidos no planejamento experimental fatorial $2^{3}$, determinou-se que as condições favoráveis para o processo de adsorção ocorrem em concentração do efluente de $50 \mathrm{mg} / \mathrm{L}$, relação massa de biomassa por volume de efluente de $0,01 \mathrm{~g} / \mathrm{mL}$ e tempo de contato da biomassa com efluente de 30min.

Na Tabela 2 são mostrados os valores da umidade final e das eficiências de adsorção obtidas para as sementes frescas e para as sementes moídas que passaram pelo processo de secagem nas diferentes condições experimentais estudadas.

Na Tabela 2 - Umidade Final e eficiência do processo de adsorção.

\begin{tabular}{ccc}
\hline Condição & Umidade final (\%) & Eficiência de adsorção (\%) \\
\hline Fresca & $84,00 \pm 1,17$ & $8,096 \pm 1,269$ \\
$T=60^{\circ} \mathrm{C}, v=2 \mathrm{~m} / \mathrm{s}$ e $h=5 \mathrm{~mm}$ & $2,82 \pm 0,17$ & $57,513 \pm 0,485$ \\
$T=60^{\circ} \mathrm{C}, v=1 \mathrm{~m} / \mathrm{s}$ e $h=5 \mathrm{~mm}$ & $3,87 \pm 0,11$ & $57,750 \pm 0,224$ \\
$T=40^{\circ} \mathrm{C}, v=2 \mathrm{~m} / \mathrm{s}$ e $h=5 \mathrm{~mm}$ & $5,21 \pm 0,18$ & $50,092 \pm 0,149$ \\
$T=40^{\circ} \mathrm{C}, v=1 \mathrm{~m} / \mathrm{s}$ e $h=5 \mathrm{~mm}$ & $6,73 \pm 0,60$ & $57,143 \pm 0,261$ \\
$T=60^{\circ} \mathrm{C}, v=2 \mathrm{~m} / \mathrm{s}$ e $h=10 \mathrm{~mm}$ & $3,58 \pm 0,13$ & $50,621 \pm 0,298$ \\
$T=60^{\circ} \mathrm{C}, v=1 \mathrm{~m} / \mathrm{s}$ e $h=10 \mathrm{~mm}$ & $3,90 \pm 0,10$ & $58,437 \pm 0,672$ \\
$T=40^{\circ} \mathrm{C}, v=2 \mathrm{~m} / \mathrm{s}$ e $h=10 \mathrm{~mm}$ & $6,29 \pm 0,42$ & $48,086 \pm 0,074$ \\
$T=40^{\circ} \mathrm{C}, v=1 \mathrm{~m} / \mathrm{s}$ e $h=10 \mathrm{~mm}$ & $7,81 \pm 1,21$ & $55,667 \pm 0,485$ \\
\hline
\end{tabular}

Observa-se na Tabela 2 que o aumento no valor da temperatura de $40{ }^{\circ} \mathrm{C}$ para $60{ }^{\circ} \mathrm{C}$ causou uma diminuição no valor da umidade final em base úmida das sementes de mamão Formosa (Carica papaya L). Este resultado está de acordo com a física do processo. Na teoria da secagem, a retirada de umidade ocorre por conta da busca pelo equilíbrio termodinâmico entre o ar circundante e o material sólido. Como modificações na temperatura do ar de secagem causam mudanças na umidade relativa do sistema (atividade de água), é esperado que em temperaturas mais elevadas, onde a atividade de água é menor, o valor da umidade do produto final seja inferior ao encontrado em temperaturas mais baixas. Em relação 
à velocidade do ar de secagem e altura da bandeja é verificado na Tabela 2 que as modificações nessas variáveis não causaram mudanças significativas nos valores da umidade final em base úmida das sementes de mamão Formosa (Carica papaya L). Estes resultados novamente condizem com a física do processo, visto que essas variáveis não interferem no equilíbrio termodinâmico do sistema. As pequenas variações que existem nos valores podem ter sido causadas por diferenças nas condições climáticas do ar ambiente entre as secagens.

Para a eficiência de adsorção, é observado na Tabela 2 que todas as biomassas moídas e secas nas diferentes condições experimentais apresentaram valores de eficiência de adsorção do corante Vermelho do Congo superiores aos encontrados para biomassa fresca. A explicação para isso está no fato de que os processos de moagem e secagem promovem um aumento na porosidade do leito, conforme demonstrado nos valores de $\varepsilon$ apresentados na Tabela 1. Esse fato pode estar influenciando positivamente o processo de adsorção, visto que quanto maior for a $\varepsilon$ de um leito de partículas maior será os espaços para o processo de transferência de massa.

Para uma melhor compreensão da influência da secagem sobre a eficiência de adsorção do corante Vermelho do Congo, é apresentado na Figura 3 o diagrama de Pareto do planejando experimental fatorial $2^{3}$ que foi efetuado para a análise da influência das variáveis temperatura do ar de secagem, velocidade do ar de secagem e altura de bandeja. Nessa figura a magnitude da influência dos efeitos sobre a resposta eficiência de adsorção é apresentada pelas colunas, enquanto que a linha transversal à coluna representa a magnitude dos efeitos com significado estatístico para $\mathrm{p}=0,05$, ou seja, os fatores que são estatisticamente significativos ao nível de $95 \%$ de confiança.

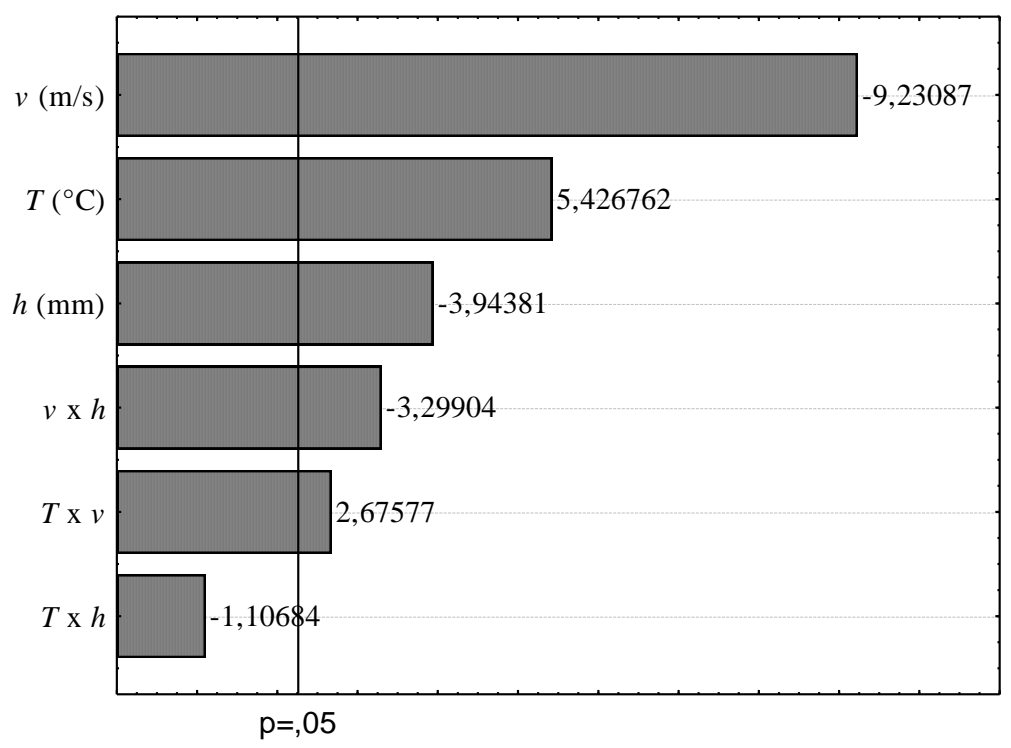

Figura 3 - Diagrama de Pareto para a análise da influência da secagem sobre a eficiência de adsorção do corante Vermelho do Congo.

Observa-se na Figura 3 que a magnitude dos efeitos, com significado estatístico para $p=0,05$, que tiveram maiores influências sobre a resposta eficiência de adsorção foram a velocidade do ar, a temperatura de secagem e a altura de bandeja. Para a velocidade do ar, é verificado que o seu aumento promove uma diminuição na eficiência de adsorção. No caso da temperatura é constatado que o seu aumento teve uma magnitude de efeito positivo, isto é, quando se modificou o valor de 40 para $60{ }^{\circ} \mathrm{C}$ acorreu um aumento na eficiência de adsorção. Já para a altura da bandeja foi obtida uma magnitude de 
efeito negativo, onde o aumento de 5 para $10 \mathrm{~mm}$ diminuiu o valor da resposta eficiência de adsorção do processo. Os dados contidos na Figura 3 mostram que a operação unitária secagem, empregada no preparo do meio adsorvente, pode influenciar significativamente a eficiência de adsorção do corante Vermelho do Congo por sementes de mamão Formosa (Carica papaya L.). Para as condições experimentais estudadas neste trabalho, a biomassa que apresentou a maior eficiência de adsorção, com valores de aproximadamente $58 \%$, foi a das sementes secas nas condições de $T=60{ }^{\circ} \mathrm{C}$ e $v=1 \mathrm{~m} / \mathrm{s}$.

\section{CONCLUSÃO}

$\mathrm{Na}$ determinação de condições favoráveis para o processo de adsorção do corante Vermelho do Congo por sementes de mamão Formosa (Carica papaya L.), conclui-se que as condições favoráveis ocorrem em concentração do efluente de $50 \mathrm{mg} / \mathrm{L}$, relação massa de biomassa por volume de efluente de $0,01 \mathrm{~g} / \mathrm{mL}$ e tempo de contato de $30 \mathrm{~min}$.

No estudo da influência do processo de secagem sobre a eficiência de adsorção do corante Vermelho do Congo por sementes de mamão Formosa (Carica papaya L.), conclui-se que a operação unitária secagem influencia significativamente a eficiência de adsorção do corante Vermelho do Congo por sementes de mamão Formosa (Carica papaya L.). Para as condições experimentais estudadas neste trabalho, a biomassa que apresentou a maior eficiência de adsorção, com valores de aproximadamente $58 \%$, foi a das sementes moídas e secas nas condições de $T=60{ }^{\circ} \mathrm{C}$ e $v=1 \mathrm{~m} / \mathrm{s}$.

\section{REFERÊNCIAS}

ARIM, A. L.; RODRIGUES, L. M.; ALMEIDA, A. R. F. Análise da adsorção do corante Vermelho do Congo utilizando semente do mamão Formosa. Anais do XIX Congresso Brasileiro de Engenharia Química, Búzios/RJ , p. 2920-2928, 2012a.

ARIM, A. L.; RODRIGUES, L. M.; ALMEIDA, A. R. F. Caracterização e análise da semente de mamão Formosa (Carica papaya L.) seca em leito fixo com escoamento de ar horizontal. Anais do $20^{\circ}$ Congresso Brasileiro de Engenharia e Ciência dos Materiais, Joinvile/SC, p. 11569-11576, 2012 b.

AXELSON, G. K.; GIORGADZE, T.; YOUGBERG, G. A. Evaluation of the use of Congo red staining in the differential diagnosis of Candida vs. various other yeast-form fungal organisms. Journal of Cutaneous Pathology, v. 35, p.27-30, 2008.

BESINELlA, E. Jr., E.; MATSUO, M. S.; WALZ, M.; SILVA, A. F.; SILVA, C. F. Efeito da temperatura e do tamanho de partículas na adsorção do corante Remazol Amarelo Ouro RNL em carvão ativado. Acta Scientiarum Technology, v. 31, n 2, p. 185-193, 2009.

BHAUMIK, M.; MCCRINDLE, R.; MAITY, A. Efficient removal of Congo red from aqueous solutions by adsorption onto interconnected polypyrrole-polyaniline nanofibres. Chemical Engineering Journal, v. 228, p. 506-515, 2013.

CALVETE, T. Casca de pinhão fresca e carvão ativo-adsorvente para remoção de corantes em efluentes aquosas. Tese de Doutorado. Programa de Pós Graduação em Química. Universidade Federal do Rio Grande do Sul. Porto Alegre, 2011.

CARDOSO, N. F. Adsorção de corantes têxteis utilizando biossorventes alternativos. Dissertação de Mestrado. Programa de Pós Graduação em Química. Universidade Federal do Rio Grande do Sul. Porto Alegre, 2012. 
CAVICHIOLO, J. R. Secagem do bagaço de laranja em secador tipo flash. Dissertação de Mestrado. Programa de Pós-graduação em Engenharia Agrícola. Universidade Estadual de Campinas. Campinas, 2011.

DURÁN, N.; MORAIS, S. G.; FREIRE, R. S. Degradation and toxicity reduction of textile effluent by combined photocatalytic and ozonation processes. Chemosphere, v. 40, p. 369-373, 2000.

FRANCO, D. S. P.; MARTINS, J. M.; RODRIGUES, L. M.; ALMEIDA, A. R. F. Análise do processo de secagem de sementes de mamão utilizado como biomassa adsorvente no tratamento de efluentes. Rev. de Ci. Exatas, RJ, EDUR, v. 27/31, n. 2, p. 44-59, 2011.

GEANKPLIS, C. J. Procesos de transporte y operaciones unitarias. $3^{\circ}$ Edição, México: CECSA, 1998.

LEVIN, L.; PAPINUTTI, L., FORCHIASSIN., F. Evaluation of Argentinean white rot fungi for their ability to produce lignin-modifying enzymes and decolorize industrial dyes. Bioresource Technology, Argentina, v. 94, n.2, p. 169-176, 2004.

MELO, M.L.S. Caracterização, estabilidade oxidativa e determinação do potencial energético do biodiesel derivado do mamão (Carica papaya L.): uma fonte não convencional. Tese de Doutorado. Programa de Pós Graduação em Química. Universidade Federal do Paraíba. João Pessoa, 2010.

MENEZES, M. L. Remoção do corante reativo azul 5G a partir de soluções aquosas utilizando o bagaço do maracujá amarelo como adsorvente. Dissertação de Mestrado. Programa de Pós Graduação em Engenharia Química. Universidade Estadual de Maringá. Maringá, 2010.

PAVAN, F. A.; MAZZOCATO, A. C.; GUSHIKEM, Y. Removal of methylene blue dye from aqueous solutions by adsorption using yellow passion fruit peel as adsorbent. Bioresour. Technol., v. 99, p. 3162-3165, 2008.

UMBUZEIRO, G. A.; OLIVEIRA, D. P.; RECH, C. M.; SALVADORI, D. M. F.; BAZO, A. P.; LIMA, R. O. A. Mutagenic and carcinogenic potential of a textile azo dye processing plant effluent that impacts a drinking water source. ScienceDirect, R. O. Alves de Lima et al. / Mutation Research v. 626 p. 53-60, 2007.

ZANONI, M. V. B.; CARNEIRO, P. A., O descarte dos corantes têxteis. Revista Ciência Hoje, v. 20, n. 174, p. 61-64, 2001.

ZHANG, Z.; MOGHADDAM, L.; O’HARA, I. M.; DOHERTY, W. O. S. Congo red adsorption by ball-milled sugarcane bagasse. Chemical Engineering Journal. v. 178, p. 122-128, 2011.

\section{AGRADECIMENTOS}

Os autores deste trabalho agradecem a Universidade Federal do Pampa - UNIPAMPA/Campus Bagé pela infraestrutura disponibilizada. 